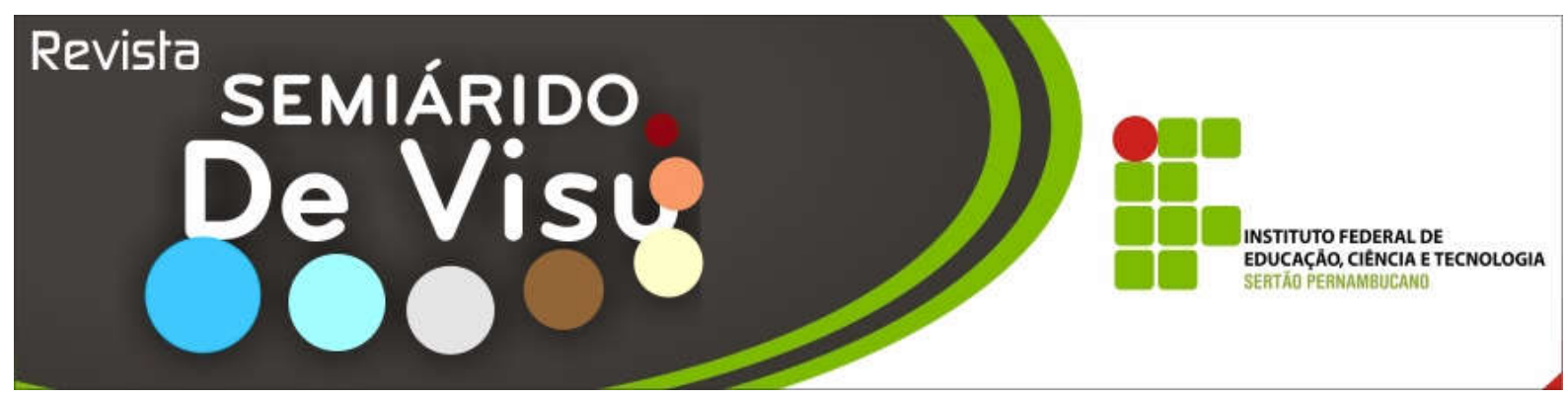

\title{
A atual situação da aplicabilidade jurídica para a geração de energia eólica
}

\author{
Nithyananda Oliveira de Queiroz Santos ${ }^{1}$, Thalita Alves de Lima $^{2}$, Alex Vieira Alves ${ }^{3}$, Vivianni \\ Marques Santos ${ }^{4}$ \\ 1,2,3,4 Univers idade Federal do Vale do São Franc isco (UNIVASF) - Campus de Juazeiro/BA. Avenida Antônio Carlos \\ Magalhães, nº. 510. Country Club, CEP: 48.902-300. Telefone/Fax: (74) 2102-7627 / E-mail: \\ 1nithya_nanda@hotmail.com; ${ }^{2}$ thalitadilima@hotmail.com; ${ }^{3}$ alex.alves@univasf.edu.br; \\ 4vivianni.santos@univasf.edu.br;
}

RESUMO: A percepção da importância da conservação do meio ambiente vem estimulando estudos sobre energias alternativas e renováveis. No cenário mundial, a energia eólica é a fonte de energia limpa com o maior potencial de crescimento para a produção de eletricidade. No Brasil, a demanda crescente por energia faz com que novas fontes energéticas sustentáveis sejam analisadas com maior interesse. O objetivo deste artigo foi analis ar a capacidade que a energia eólica tem apres entado com seu potencial energético, causando impactos substancialmente menores do que as outras fontes renováveis e não renováveis. Os resultados demonstram que a energia eólica independe dos combustíveis fósseis e contribui para redução da emissão de gás carbônico. Tudo isso foi detalhado sob a ótica da legislação brasileira, segundo a qual são definidos os requisitos apenas para instalação das indústrias produtoras de energia, incluindo os parques eólicos, sendo necessário que se crie uma legis lação permanente, com regras estabelecidas e subsídios definidos, para que as empresas possam interagir e se empenhar com estudos, apoio técnico e investimentos.

Palavras-chave: Meio ambiente, energias renováveis, rela tório de impacto ambiental, legis lação.

\section{The current situation of legal applicability for wind power production}

\begin{abstract}
The perception of the importance of the environment conservation has stimulated studies about alternative and renewables energies. In world, wind power is a clean energy source with the largest growth potential for the production of electricity. In world scenario, the growing demand for energy makes new sustainable energy sources are analyzed with greater interest. The aim of this study was to analyze the ability of wind power have presented with its potential energy, impacting substantially lower than other renewab le and non-renewable. The results ind ic ated that wind power is independent of fossil fuels and contributes to reducing carbon dioxide emis sions. All this was detailed from the perspective of Brazilian legis lation that defines only the requirements for installation of the energy's industry, including wind farms, being necessary to create a permanent legis lation, with defined rules and subsid ies so that companies can interact and engage with studies, technic al ass istance and investment.
\end{abstract}

key words: Env ironment, Renewable Energy, Env ironmental Impact Report, leg is lation. 
(SANTOS et al., 2015)

\section{Introdução}

$\mathrm{N}$

o mundo moderno, as fontes de energia são extremamente importantes. Logo após a Revolução Industrial, houve uma aceleração no processo de urbanização, aumentando a demanda por eletricidade e até hoje o seu consumo é crescente. A população tornou-se dependente de recursos energéticos para o funcionamento tanto no âmbito doméstico quanto industrial.

Paralelamente ao avanço da dependência por energia, grandes problemas socioambientais foram gerados, pois a maioria das fontes utilizadas para obtê-la era de origem fóssil (carvão, gás natural, petróleo) e a sua queima é nociva ao meio ambiente, uma vez que libera vários gases poluentes na atmosfera, provocando o efeito estufa e contaminando de maneira geral os recursos hídricos.

Atualmente, sabe-se que a energia não deve ser obtida totalmente de recursos fósseis, porque a situação ambiental pode agravar ainda mais o problema das mudanças climáticas. Muito tem que ser feito para que ocorram avanços significativos no uso das fontes alternativas de energia limpa para que elas sejam capazes de se inserir em uma nova economia, onde os limites ambientais do planeta devam ser respeitados. É um desafio para todo o planeta gerar energia com a menor emissão possível de carbono, a fim de atender às questões climáticas e, ao mesmo tempo, prover segurança e estabilidade energética para as gerações futuras.

No continente sulamericano, o Brasil Possui o mercado mais promissor para o desenvolvimento da energia eólica, visto que o vento é uma fonte de energia disponível em abundância com potencial atestado nos mais diversos parques eólicos do território brasileiro. A energia eólica além de ter como benefício o fato de ser uma energia limpa, elimina os custos dos demais combustíveis, reduzindo os riscos prolongados de outras fontes, eliminando também a dependência econômica e política pela importação de energia a outros países.

Este artigo tem como objetivo analisar a possibilidade do uso de novas fontes alternativas de energia diante da legislação brasileira e os requisitos necessários para construção e operação de parques eólicos no país. A mudança da matriz energética do país é um grande passo e precisa de regulamentação. Faz-se necessária a criação de políticas públicas de incentivo á produção e utilização das energias renováveis e limpas, incentivo à pesquisa e à transferência de tecnologia, decisão sobre investimento nessa modificação. Com isso, o Brasil tem uma grande oportunidade de se expandir através do aumento do consumo de energia sem que isso implique em altas taxas de emissões de gases de efeito estufa (GEE), ou seja, desenvolver-se com qualidade e sustentabilidade.

\section{Material e métodos}

Esse estudo caracterizou-se por ser uma pesquisa de caráter qualitativo, pois traz informações de caráter subjetivo. Também é considerado qualitativo por não serem utilizadas técnicas estatísticas na elucidação da problemática (GIL, 2006).

Para análise da situação atual da aplicabilidade jurídica para a produção de energia eólica, ou seja, geração de energia a partir da força dos ventos, cuja quantidade de energia transferida é função da densidade do ar, da área coberta pela rotação das pás (hélices) e da velocidade do vento, fez-se necessário analisar criticamente com base na utilização da energia eólica na matriz energética brasileira e principalmente na legislação brasileira.

Foi utilizada a pesquisa bibliográfica como procedimento técnico, que parte do referencial teórico com base em estudos e pesquisas em livros, artigos científicos e sites da internet. De acordo com Gil (2006), "A principal vantagem da pesquisa bibliográfica reside no fato de permitir ao investigador a cobertura de uma gama de fenômenos muito mais ampla do que aquela que poderia pesquisar diretamente".

Além disso, foram realizadas visitas técnicas à empresa localizada no estado da Bahia, onde foram obtidas informações sobre o 
(SANTOS et al., 2015)

processo de geração de energia elétrica a partir da força dos ventos.

\section{Resultados e Discussão}

\section{Potencial eólico para produção de energia limpa}

As fontes convencionais de energia causam um impacto ambiental e social de grande proporção, o que provoca um debate sobre a busca pelo desenvolvimento tendo como prioridade um planeta limpo e saudável, aproveitando melhor os recursos naturais, reduzindo a poluição, a exemplo da redução de gás carbônico na atmosfera.

Dentre as fontes existentes de energia renovável, a energia eólica é a que vem obtendo o maior sucesso, demandando significativa atenção. Na Figura 1, observa-se que nos últimos 16 anos, segundo o relatório publicado pelo Conselho Global de Energia Eólica (GWEC - Global Wind Energy Council), a capacidade de geração de en ergia eólica no mundo passou de $6,1 \mathrm{GW}$ para 282,4 GW, de modo que no ano de 2012 a capacidade de geração correspondeu a mais de 46 (quarenta e seis) vezes o valor registrado em 1996.

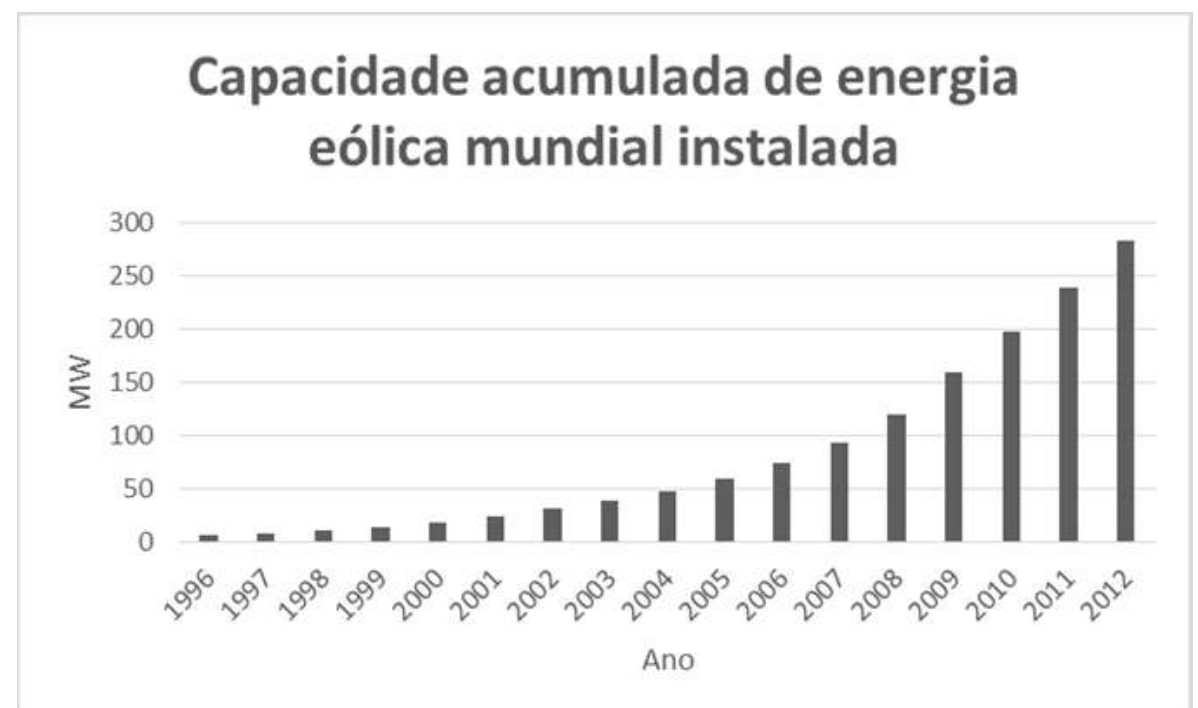

Figura 1. Capacidade acumulada de energia eólica mundial instalada. Adaptada de GWEC, 2012.

É importante ressaltar os benefícios sociais e econômicos trazidos por essa nova forma de energia elétrica, principalmente na redução de gases poluentes e na geração de empregos.

A busca pelo desenvolvimento sustentável é almejada e está relacionada com economia, meio ambiente e sociedade. Depois de agredir a natureza por muitos anos, e conhecendo as consequências como chuva ácida, aquecimento global, lixo atômico, risco de desastres com os combustíveis nucleares e fósseis, a humanidade busca formas de reparar os danos causados recompondo ou compensando o que já foi destruído.

Em decorrência da melhoria da qualidade de vida nos países emergentes, com o crescimento na economia mundial, verifica-se uma demanda crescente no consumo de en ergia elétrica. Entre 2000 e 2020 é previsto um crescimento mundial de $57 \%$ no consumo de energia, segundo o Ministério de Minas e Energia (MME). A Figura 2 contém o consumo de energia mundial desde a década de 70 e aquela prevista até 2020 . 
(SANTOS et al., 2015)

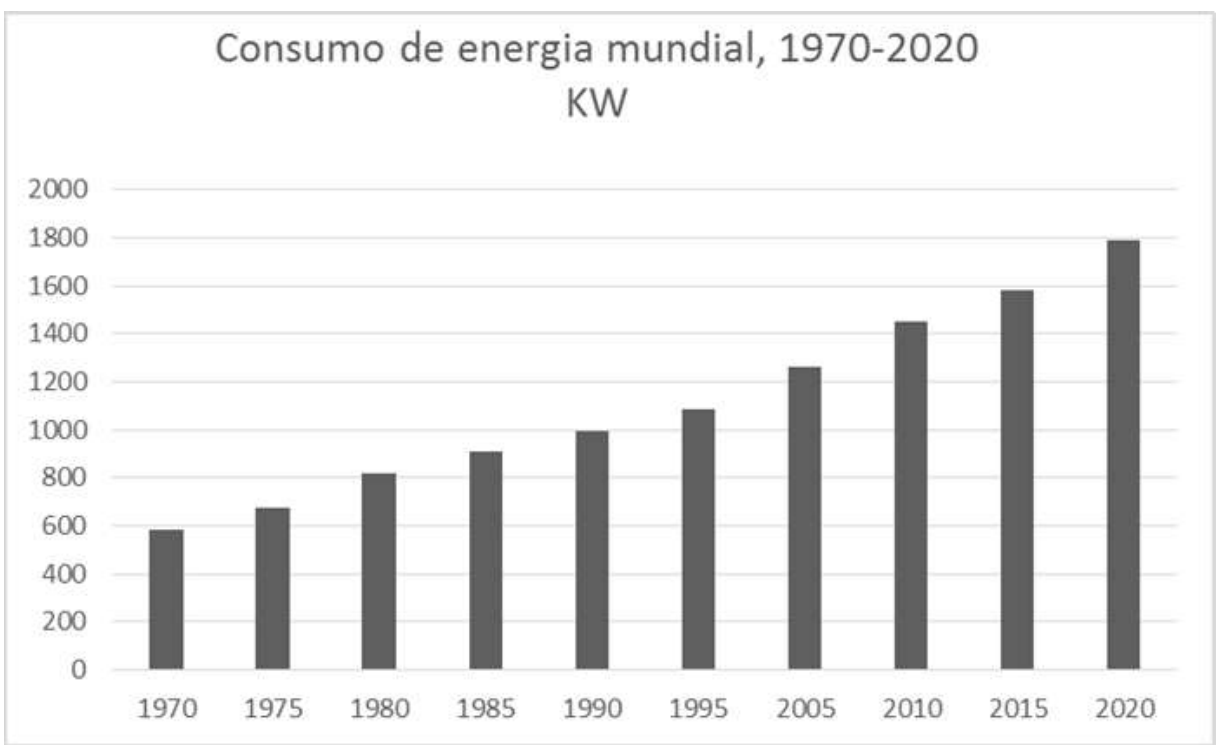

Figura 2. Consumo mundial de energia. Adaptada de EIA(2001).

\section{Importância da utilização das energias} renováveis

As matrizes energéticas mais comuns são as usinas hidrelétrica, termelétrica $\mathrm{e}$ nuclear. Nas usinas hidrelétricas, a água é a fonte geradora de energia. Não é uma energia poluente e, teoricamente, a água é renovável. Há quem diga que a geração hidrelétrica é sustentável, porém, estudos mostram que, se nada for feito, a água pode acabar, e pode ocorrer um retrocesso insustentável. Apesar de ser uma produção de energia limpa, a construção de usinas hidrelétricas podem causar impactos ambientais negativos e em épocas de hidrologias desfavoráveis, as disponibilidades hidrelétricas podem não ser suficientes para atender a demanda crescente (SOUSA, 2010).

Segundo o Plano Decenal de Expansão de Energia (PDE) 2021 (BRASIL-a, 2012), as usinas que mais emitem gás carbônico $\left(\mathrm{CO}_{2}\right)$ são as termelétricas. A sua eficácia se dá através do vapor de água produzido por uma caldeira aquecida pela queima de combustíveis fósseis (carvão e petróleo). Essa queima de combustíveis fósseis lança na atmosfera uma grande quantidade de $\mathrm{CO}_{2}$.Usinas nucleares sem dúvida apresentam um risco enorme a sociedade. Um vazamento nuclear pode causar danos irreversíveis à população e prejudicar o meio ambiente e toda a vida existente na área afetada.

Devido a crescente geração de $\mathrm{CO}_{2} \mathrm{e}$ às crises de geração de energia elétrica, a necessidade de construir parques eólicos se mostrou imprescindível, de modo que a implantação de políticas de incentivos, regulamentação e financiamentos para o desenvolvimento da energia eólica foram elaboradas por vários países (SIMAS, 2012). Nesses parques são encontrados aerogeradores, construídos com grandes turbinas que, aproveitando a força mecânica das hélices, acumu lam energia elétrica que são levadas às linhas de transmissão e às subestações. Adicionalmente, parques eólicos geram empregos, atraem investimentos à região, induzem um crescimento nas atividades econômicas do país. Entre outras vantagens, um parque eólico leva em média o prazo de dois anos para ser instalado, ao passo que uma usina elétrica levará pelo menos cinco anos para a conclusão das obras necessárias a sua instalação (BRASIL-b, 2010). Tem-se, por consegu inte, uma redução de três anos desse período para o caso da construção de um parque eólico.

No Brasil, segundo a ABEEólica, o mês de março de 2013 iniciou com 2,583GW de potência eólica instalada (Figura 3), distribuída em 111 parques eólicos, 
(SANTOS et al., 2015)

representando um crescimento de quase $3 \%$ de potência e um acréscimo de 3 parques eólicos em relação a Janeiro de 2013, quando existiam 108 parques e $2,509 \mathrm{GW}$.

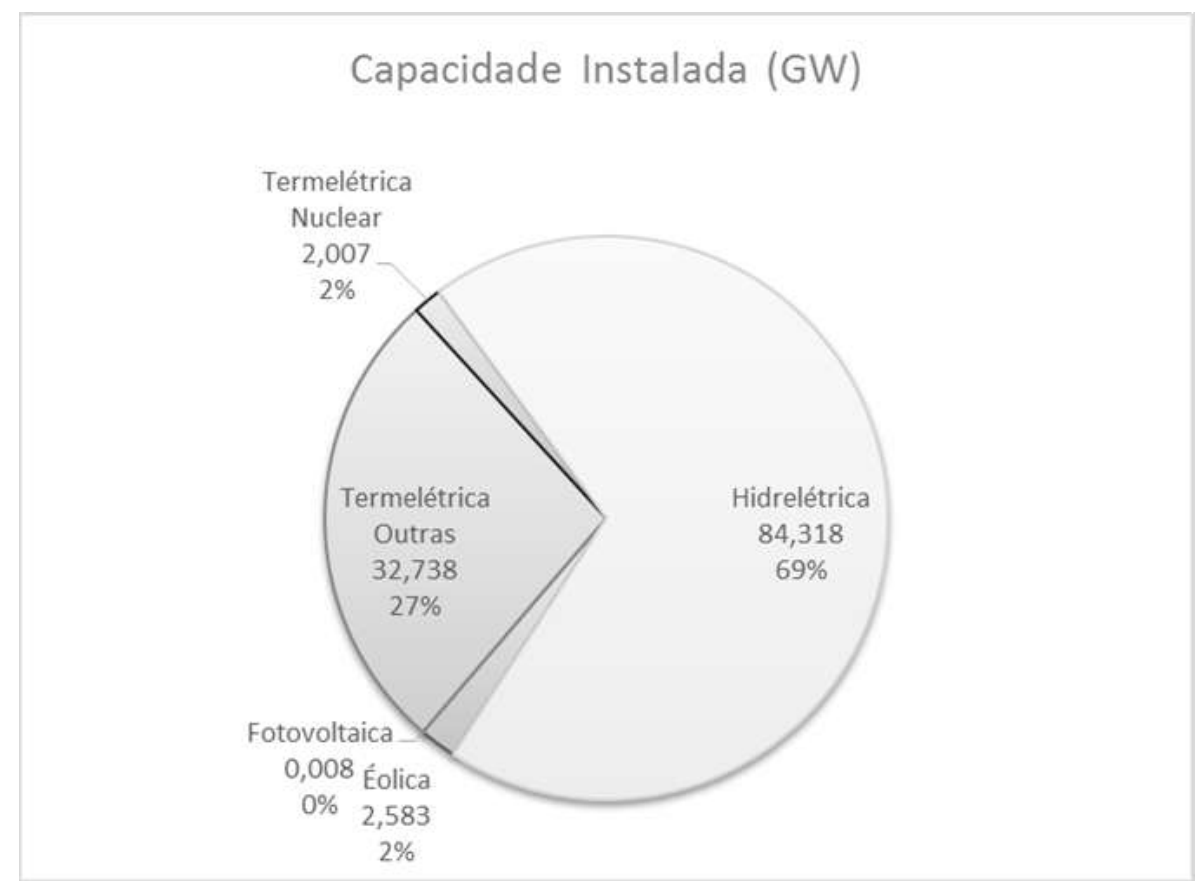

Fig ura 3. Matriz energética brasileira. Adaptada de ABBEólica, 2013.

O crescimento observado é importante, pois mostra que esta fonte renovável de energia está em ascensão, principalmente a partir do ano de 2013. Na Figura 3 pode-se visualizar a participação das fontes na matriz energética brasileira em março de 2013. Apesar da importância da energia eólica, esta fonte ainda é pouco utilizada, representado apenas $2 \%$ da capacidade instalada brasileira. Esta contribuição é a mesma oriunda da fonte nuclear, cuja dificuldade de instalação e operação, bem como os riscos envolvidos, em função da possibilidade de acidentes, são consideravelmente maiores.

A principal característica do desenvolvimento sustentável a partir de energia limpa está na fonte geradora de energia, que deve ser inesgotável. Outro fator, tão importante quanto a sua característica renovável, é a redução ou não emissão de gases poluentes no meio ambiente. Segundo a ABEEólica, o setor energético representa cerca de $70 \%$ dos gases de efeito estufa, e o principal fator é a queima de combustíveis fósseis para a geração de en ergia térmica e elétrica.

\section{Legislação aplicada às energias renová veis}

O aumento crescente do preço do barril de petróleo, bem como a possibilidade do seu "esgotamento" para as próximas gerações, tem motivado a busca por fontes alternativas de energia. As estimativas da Agência Internacional de Energia (AIE) mostram que se a média de consumo das últimas décadas se mantiver, as reservas de petróleo e gás natural irão se esgotar em 100 anos e as de carvão, em 200 anos. Além disso, os racionamentos de energia elétrica e o acirramento das questões ambientais fazem com que empresas e pessoas procurem outras formas de energia para suprir as suas necessidades. Diante disso, novas companhias de energias renováveis estão consolidando a sua participação no mercado mundial.

No tocante à mudança climática, o cenário mundial instalado está forçando o Congresso Nacional do Brasil a estabelecer uma legislação para as energias renováveis. Entretanto, segundo notícias do Greenpeace, organização não governamental que atua 
(SANTOS et al., 2015)

internacionalmente em questões relacionadas à preservação do meio ambiente $\mathrm{e}$ desenvolvimento sustentável, atualizada em outubro de 2011, o Projeto de Lei 630/2003 do deputado Roberto Gouveia está paralisado desde o final de 2009 na Câmara Federal, aguardando Deliberação de Recurso na Mesa Diretora da Câmara dos Deputados. Este Projeto de Lei também é conhecido como Lei de Renováveis, através do qual foi criado um fundo, que receberia $8 \%$ dos recursos provenientes da Compensação Financeira pela Utilização de Recursos Hídricos, para financiar projetos e programas de pesquisa científica e tecnológica e a produção de insumos e equipamentos para geração. Além disso, propôs a alocação de subsídios para fontes de geração limpa e assegura a elas prioridade na ligação com a rede de distribuição de energia nacional, amplia a quantidade de energia limpa comercializada no país e abre o caminho para a geração descentralizada, prevendo, inclusive, que brasileiros individualmente possam gerar energia em suas próprias casas e jogar o excedente na rede elétrica.

O projeto de lei 630/2003 juntamente com os seus apensados já receberam 22 emendas. A Câmara anexou a este projeto os seguintes PL's: 3259/2004 (cria o Programa de Incentivo às Energias Renováveis), PL 523/2007 (institui a Política Nacional de Energias Alternativas), 5248/2005 (institui o Programa de Geração de Energia a partir do Lixo), 7692/2006 (institui o Programa Brasileiro de Descentralizada) 2023/2007 (institui incentivos fiscais para energia solar, eólica ou outras fontes alternativas), 2505/2007 (cria o Certificado de Empreendedor de Energia Renovável), 3004/2008 (dispõe sobre a criação do Programa Nacional de Biogás), 4550/2008 (dispõe sobre a produção e comercialização de energia de fontes incentivadas e renováveis), 4798/2009 (institui o Código Brasileiro de Sustentabilidade Energética).

O projeto de lei $n^{\circ} 523 / 2007$, de autoria do Deputado Antonio Carlos Mendes Thame, do PSDB de São Paulo, institui a Política Nacional de Energias Alternativas, bem como, os princípios e as diretrizes nacionais para a expansão, o desenvolvimento e a propagação do uso das energias alternativas nos combustíveis fósseis, além de incentivos ao desenvolvimento tecnológico das fontes alternativas de en ergia e a mudança da matriz energética brasileira pra uma matriz limpa. Trata também dos mecanismos financeiros, econômicos, tributários e creditícios para que a transformação ocorra de fato. Nesse contexto, se encaixa a geração de energia por meio dos biocombustíveis, energia eólica, de biomassa, solar, térmica e voltaica, energia de marés e de fontes termais subterrâneas e qualquer outra que não seja advinda de fontes fósseis. $\mathrm{O}$ projeto diz ainda que $25 \%$ da geração de energia brasileira deveriam ser obtidos a partir de fontes alternativas, e, em 2030, aumentar para $35 \%$, essa porcentagem. Nessa linha, prevê também a proibição de concessão de licenças ambientais para projetos convencionais, mesmo em fase de instalação e operação, se já iniciados, caso o percentual anteriormente estabelecido não seja atingido.

Atualmente, os custos para se obter energia através de fontes alternativas são mais altos do que as fontes convencionais. Em abril de 2002 o Governo Federal instituiu a Lei ${ }^{\circ}$ 10.438, que instituiu o Programa de Incentivos às Fontes Alternativas de Energia Elétrica Proinfa, tendo como objetivo ampliar a participação das fontes alternativas na matriz elétrica (NASCIMENTO, 2010). Na primeira fase, seriam instalados $3.300 \mathrm{MW}$ de potência no sistema elétrico interligado - sendo 1.423 MW de usinas eólicas, $1.192 \mathrm{MW}$ de pequenas centrais hidrelétricas $(\mathrm{PCH})$ e $685 \mathrm{MW}$ de biomassa (MME, 2013).

De acordo com o Ministério de Minas e Energia - MME, o Proinfa é um programa precursor, que incentivou novas fontes de energia, especialmente a eólica, diante das condiçõ es climáticas favoráveis do paísO Brasil passou, em pouco mais de 3 anos, de cerca de 22 MW de en ergia eólica instalada, em 2010, para os atuais 414 MW instalados, e, em breve, mais 1008,92 MW previstos serão concluídos (MME, 2013).

O desafio estabelecido pelo Proinfa foi nacionalizar $60 \%$ dos empreendimentos que têm como objetivo principal fomentar a 
(SANTOS et al., 2015)

indústria de base dessas fontes limpas de energia. Se considerarmos o domínio de conhecimento de todo o processo dentro da cadeia produtiva, o país está em desvantagem, pois não possui o know-how que envolve a geração de energia a partir dos ventos. Entretanto, várias empresas estrangeiras se interessaram por estudos de viabilidade técnica para implementação de grandes parques eólicos no Brasil, de acordo com o Ministério do Meio Ambiente - MMA (BRASIL, 2013). Dados do MME apresentam 1,4 GW de projetos já contratados no Proinfa, quatro em operação, representando $158,3 \mathrm{MW}$, e 50 parques em implantação, representando 1.264,6 MW. E mais, cerca de 3,5 GW, em projetos eólicos autorizados pela Agência Nacional de Energia Elétrica (Aneel) que não integram a carteira de projetos do Proinfa.

Para instalar parques eólicos no Brasil, a legislação vigente determina que sejam feitas análises de impacto ambiental, a saber, Avaliação de Impacto Ambiental (AIA) formada por um conjunto de procedimentos que assegure, desde o início do programa, a execução de um exame sistemático dos impactos ambientais da ação proposta e suas alternativas, para que os resultados sejam apresentados ao público e aos responsáveis pela tomada de decisão; Estudo de Impacto Ambiental (EIA) trata-se do estudo deexecução, feito por uma equipe multidisciplinar, das tarefas técnicas e científicas que analisarão, sistematicamente, as consequências da implantação do projeto no meio ambiente, por meio de métodos de AIA e técnicas de previsão dos impactos ambientais; o Relatório de Impacto Ambiental (RIMA) é o documento que apresenta os resultados dos estudos técnicos e científicos de avaliação de impacto ambiental, compondo o documento do processo de avaliação de impacto ambiental, com o objetivo de esclarecer todos os elementos da proposta (EMA, 2013).

$$
\text { A RESOLUÇÃO CONAMA (O }
$$
CONSELHO NACIONAL DO MEIO AMBIENTE - IBAMA) $\mathrm{N}^{\circ} 001$, de 23 de janeiro de 1986, Publicado no D.O.U de 17 de fevereiro de 1986, de autoria de Flávio Peixoto da Silveira (Alterada pela Resolução $n^{\circ}$ 011/86) conclui que::

$$
\begin{aligned}
& \text { impacto ambiental é qualquer alteração das } \\
& \text { propriedades físicas, químicas e biológic as } \\
& \text { do meio ambiente, causada por qualquer } \\
& \text { forma de matéria ou energia resultante das } \\
& \text { atividades humanas que, direta ou } \\
& \text { indiretamente afetam: (I) a saúde, a } \\
& \text { segurança e o bem-estar da população; (II) } \\
& \text { as atividades sociais e econômicas; (III) a } \\
& \text { biota; (IV) as condições es téticas e } \\
& \text { sanitárias do meio ambiente; (V) a } \\
& \text { qualidade dos recursos ambientais } \\
& \text { (Resolução CONAMA No 001). }
\end{aligned}
$$

Do artigo $2^{\circ}$ ao $4^{\circ}$ desta resolução é destacada a necessidade do estudo de impacto ambiental e do relatório de impacto ambiental RIMA que será submetido à aprovação do órgão estadual competente, além do IBAMA que atua em caráter supletivo para o licenciamento de atividades modificadoras do meio ambiente. Fica a cargo dos órgãos ambientais competentes e dos órgãos setoriais do SISNAMA (Sistema Nacional do Meio Ambiente) compatibilizar os processos de licenciamento com as etapas de planejamento e implantação das atividades modificadoras do meio Ambiente, respeitados os critérios e diretrizes estabelecidas e tendo por base a natureza, o porte e as peculiaridades de cada atividade.

O estudo de impacto ambiental, além de atender à legislação e em especial aos princípios e objetivos expressos na Lei de Política Nacional do Meio Ambiente, deverá contemplar todas as alternativas tecnológicas e de localização de projeto, confrontando-as com a hipótese de não execução do projeto; identificar e avaliar sistematicamente os impactos ambientais gerados nas fases de implantação e operação da atividade; definir os limites da área geográfica a ser direta ou indiretamente afetada pelos impactos, denominada área de influência do projeto, considerando, em todos os casos, a bacia hidrográfica na qual se localiza; considerar os planos e programas governamentais, propostos e em implantação na área de influência do projeto, bem como a sua compatibilidade. 
Neste estudo devem constar as atividades técnicas desenvolvidas, a saber, diagnóstico ambiental da área de influência do projeto, completa descrição e análise dos recursos ambientais e suas interações, tal como existem, de modo a caracterizar a situação ambiental da área, antes da implantação do projeto; análise dos impactos ambientais do projeto e de suas alternativas, através de identificação, previsão da magnitude e interpretação da importância dos prováveis impactos relevan tes, discrimin ando os impactos positivos e negativos (benéficos e adversos), diretos e indiretos, imediatos e a médio e longo prazo, temporários e permanentes; seu grau de reversibilidade; suas propriedades cumulativas e sinérgicas; a distribuição dos ônus e benefícios sociais; definição das medidas mitigadoras dos impactos negativos, entre elas os equipamentos de controle e sistemas de tratamento de despejos, avaliando a eficiência de cada uma delas; e elaboração do programa de acompanhamento e monitoramento (os impactos positivos e negativos, indicando os fatores e parâmetros a serem considerados). $\mathrm{O}$ artigo $9^{\circ}$ traz o detalhamento do relatório de impacto ambiental - RIMA. Nele, devem estar descritos os objetivos $\mathrm{e}$ as justificativas do projeto, sua relação e compatibilidade com as políticas setoriais, planos e programas governamentais; a descrição do projeto e suas alternativas tecnológicas, especificando para cada um deles, nas fases de construção e operação a área de influência, as matérias primas, e mão-de-obra, as fontes de energia, os processos e técnicas operacionais, os prováveis efluentes, emissões, resíduos de energia, os empregos diretos e indiretos a serem gerados; a síntese dos resultados dos estudos de diagnósticos ambiental da área de influência do projeto; a descrição dos prováveis impactos ambientais da implantação e operação da atividade, considerando o projeto, suas alternativas, os horizontes de tempo de incidência dos impactos e indicando os métodos, técnicas e critérios adotados para sua identificação, quantificação e interpretação; a caracterização da qualidade ambiental futura da área de influência, comparando as diferentes situações da adoção do projeto e suas alternativas, bem como com a hipótese de sua não realização; a descrição do efeito esperado das medidas mitigadoras previstas em relação aos impactos negativos, mencionando aqueles que não puderam ser evitados, e o grau de alteração esperado; o programa de acompanhamento e monitoramento dos impactos; recomendação quanto à alternativa mais favorável (conclusões e comentários de ordem geral).

Nesta mesma resolução do CONAMA destaca-se que:

o Relatório de Impac to Ambiental deve ser descritas de forma objetiva e adequada à sua compreensão. As informaçõ es devem ser traduzidas em linguagem acessível, ilustradas por mapas, cartas, quadros, gráfic os e demais técnicas de comunicação $\mathrm{v}$ isual, de modo que se possam entender as vantagens e desvantagens do projeto, bem como todas as consequências ambientais de sua implantação. Os órgãos públicos que manifestarem interesse, ou tiverem relação direta com o projeto, receberão cópia do RIMA, para conhecimento e manifestação. Ao determinar a execução do estudo de impacto ambiental e apresentação do RIMA, o estadual competente ou o IBAMA ou, quando couber o Município, determinará o prazo para recebimento dos comentários a serem feitos pelos órgãos públicos e demais interessados e, sempre que julgar necessário, promoverá a realização de audiência pública para informação sobre o projeto e seus impactos ambientais e discuss ão do RIMA (Resolução CONAMA No 001).

O fato de haver uma resolução que determine os pontos a serem seguidos para a instalação dos parques eólicos que se refere às questões de impacto ambiental não é suficiente para regulamentar o setor energético. Ainda há uma deficiência no que diz respeito à criação de leis que estabeleçam capacidade de produção, distribuição e utilização. Para o então presidente, em 2009, do Instituto do Desenvolvimento de Energias Alternativas da América Latina - Ideal, Mauro Passos, (MUDANÇAS CLIMÁTICAS, 2009) "um dos principais obstáculos para o Brasil avançar no setor de energias renováveis é a falta de visão 
(SANTOS et al., 2015)

pró-ativa por parte do corpo funcional de órgãos governamentais, como a Empresa de Pesquisa Energética (EPE), a Eletrobrás e o Ministério de Minas e Energia". Ainda de acordo com Mauro Passos, o Brasil está perdendo a oportunidade de se tornar uma liderança em energias renováveis por três motivos: (1) ampliação de termelétricas que utilizam combustíveis fósseis como fonte primária; (2) forte aposta na exploração do présal; e (3) ausência de investimento governamental diretamente em energias renováveis.

Com relação ao primeiro motivo apontado, o Ministério de Minas e Energia escolheu expandir o uso das fontes provenientes dos combustíveis fósseis para garantir um custo menor de energia e afastar o risco de apagão, fundamentada na segurança energética e desde então não se manifestou claramente para inserir novas fontes de energia na matriz energética brasileira. Quanto a forte aposta na exploração do pré-sal, os investimentos maciços no indicam que o Brasil está indo em um movimento contrário ao movimento internacional de migração para uma economia com uso de menos carbono. Por fim, os recursos advindos do governo não são aplicados em ações que integram diversos programas e como não há um orçamento específico para as energias renováveis, não é possível medir quanto o país investe nas energias alternativas.

Diante do exposto, o governo, até esta data, não encarou a problemática deste estudo com a devida importância, sendo recomendada uma visão estratégica do potencial das energias eólica. Isso acontece, possivelmente, porque o quadro funcional das empresas públicas de energia ainda segue o modelo da matriz energética da década de 70. Além disso, o governo não se prontificou a priorizar e incluir a energia eólica de forma mais efetiva nas discussões dos planos já existentes e futuros.

\section{Conclusões}

Com a possibilidade de esgotamento das fontes de energia de origem fóssil como o petróleo e o gás natural, há hoje uma necessidade de alterar a matriz energética mundial buscando por fontes de energias sustentáveis. A degradação de recursos e ambientes e seus efeitos nocivos, as disparidades sociais e econômicas, a superpopulação fez brotar o desafio de gerar energia com menor emissão de carbono e outros gases poluentes.

É cada vez mais necessária à criação e implementação de políticas públicas de incentivo a energias renováveis e limpas. O Brasil, mesmo possuindo um pequeno percentual da energia produzida proveniente de fontes limpas, apresenta incentivos maciços para ampliação de termelétricas e investimentos na exploração de petróleo, com a descoberta da camada pré-sal em comparação aos investimentos na geração de energia limpa, como a eólica. Dessa forma, falta, para o país, visão estratégica por parte dos órgãos responsáveis pela condução da política energética, como o Ministério de Minas e Energia.

Apesar da ampla discussão sobre os biocombustíveis, a energia eólica ainda é pouco discutida diante do biodiesel e etanol. Dessa forma, o Brasil precisa de uma legislação perene, com regras estabelecidas e subsídios definidos o mais rápido possível. Somente assim, o setor empresarial poderá se envolver e se comprometer com investimentos, contribuindo para que o país seja capaz de crescer e se destacar como produtor de en ergia eólica diante do seu potencial de geração.

Para que haja mudança no cenário brasileiro, é preciso que se crie uma legislação permanente, com regras estabelecidas e subsídios definidos, para que as empresas possam interagir e se empenhar com estudos, apoio técnico e investimentos. Sendo assim, ainda se espera pela votação do Projeto de Lei 630 , de 2003, que se refere aos incentivos para o desenvolvimento de fontes de energias renováveis no Brasil e alteram a legislação vigente e o Programa de Incentivo às Fontes Alternativas (Proinfa), para que uma posição seja tomada frente às necessidades que já estão impostas a todos, tanto às pessoas como às organizações. 
(SANTOS et al., 2015)

Por derradeiro, é crucial que o Brasil promova uma revolução tecnológica no setor e na matriz energética brasileira, considerando que as futuras gerações dependem de uma postura ativa e responsável na condução desse projeto de renovação sustentável das fontes energéticas brasileiras, sem perder de $v$ ista $o$ desenvolvimento econômico tão sonhado, harmonizando os interesses do homem e do planeta como um todo.

\section{Referências}

ABBEOLICA. Boletim Dados ABEEólica. 2013. Disponível em: $<$ http://www.abeeolica.org.br/index.php/dados. html $>$. Acessado em: 10 abr. 2013.

BRASIL, Ministério do meio ambiente. Conselho Nacional do Meio Ambiente. 2013. Disponível em: <www.mma.gov.br $>$. Acessado em: 28 març. 2013.

BRASIL-a. Ministério de Minas e Energia. Plano decenal de expansão de energia: 2021. Brasília: MME, 2012. 386 p. Disponível em: $<$ http://www.epe.gov.br/PDEE/20120924_1.pd f>. Acessado em: 8 abr. 2013.

BRASIL-b. Governo do Estado do Ceará. Atração de investimento no Estado do Ceará Mapa territorial de parques eólicos. Fortaleza, $2010 . \quad$ Disponível em: $<$ http://www.adece.ce.gov.br/index.php/br/dow nloads/category/5-energia $>$. Acessado em: 4 abr. 2013.

EIA. Energy Information Administration, International Energy Outlook. 2001. Disponível em $\quad<$ http://www.eia.doe.gov/oiaf/ieo/>. Acessado em: 10 de abril de 2013.

EMA, Engenharia de Meio Ambiente. Disponível em: $<$ http://www.emaeng.com.br/site/unico.aspx? id Noticia $=150>$. 2013. Acessado em: 08 abr. 2013.

GWEC. Global Wind Statiste 2012. Global Wind Energy Countil. 2012. Disponível em:
$<$ http://www.gwec.net/wpcontent/uploads/2013/02/GWEC-PRstats2012 english.pdf $>$. Acessado em: 10 abr. 2013.

GIL, A. C. Métodos e Técnicas de Pesquisa Social. 5. ed. São Paulo: Atlas, 2006. 94 p.

MME. Ministério de Minas e Energia. 2013. Disponível em: <http://www.mme.gov.br/>. Acessado em: 08 abr. 2013.

MUDANÇAS CLIMÁTICAS. Informações e reflexões para um jornalismo contextualizado. $2009 . \quad$ Disponível em: $<$ http://www.mudancasclimaticas.andi.org.br/n ode/1127?page $=0,2>$. Acessado em: 10 abr. 2013.

NASCIMENTO, M. Direito Ambiental e as Energias Limpas. Revista Âmbito Jurídico, Rio Grande, XIII, 74, 2010.

SIMAS, M. S. Energia eólica e desenvolvimento sustentável no Brasil: estimativa da geração de empregos por meio de uma matriz insumo-produto ampliada. Dissertação (Mestrado em Ciências). Universidade de São Paulo. Escola Politécnica / Faculdade de economia e administração / Instituto de Eletrotécnica e Energia / Instituto de Física. 2012.

SOUSA, W. S. Impacto ambiental de hidrelétricas: uma análise comparativa de suas abordagens. Dissertação (Mestrado em Ciências). Universidade Federal do Rio de Janeiro. COOPPE/UFRJ/Programa de planejamento estratégico. 2010. 